\title{
BMJ Open End-of-life outcomes with or without early palliative care: a propensity score matched, population-based cancer cohort study
}

\author{
Hsien Seow (D) , ${ }^{1,2}$ Rinku Sutradhar, ${ }^{2,3}$ Fred Burge, ${ }^{4}$ Kimberlyn McGrail, ${ }^{5}$ \\ Dawn M Guthrie, ${ }^{6}$ Beverley Lawson, ${ }^{4}$ Urun Erbas Oz, ${ }^{2}$ Kelvin Chan, ${ }^{7}$ \\ Stuart Peacock, ${ }^{8}$ Lisa Barbera ${ }^{9}$
}

To cite: Seow H, Sutradhar R, Burge F, et al. End-of-life outcomes with or without early palliative care: a propensity score matched, population-based cancer cohort study. BMJ Open 2021;11:e041432. doi:10.1136/ bmjopen-2020-041432

- Prepublication history and additional material for this paper is available online. To view these files, please visit the journal online (http://dx.doi.org/10. 1136/bmjopen-2020-041432)

Received 08 June 2020 Revised 15 December 2020 Accepted 26 January 2021
Check for updates

(C) Author(s) (or their employer(s)) 2021. Re-use permitted under CC BY-NC. No commercial re-use. See rights and permissions. Published by BMJ.

For numbered affiliations see end of article.

Correspondence to

Dr Hsien Seow;

seowh@mcmaster.ca

\section{ABSTRACT}

Objectives To investigate whether cancer decedents who received palliative care early (ie, $>6$ months before death) and not-early had different risk of using hospital care and supportive home care in the last month of life.

Design/setting We identified a population-based cohort of cancer decedents between 2004 and 2014 in Ontario, Canada using linked administrative data. Analysis occurred between August 2017 to March 2019.

Participants We propensity-score matched decedents on receiving early or not-early palliative care using billing claims. We created two groups of matched pairs: one that had Resident Assessment Instrument (RAl) home care assessments in the exposure period (Yes-RAl group) and one that did not (No-RAl group) to control for confounders uniquely available in the assessment, such as health instability and pain. The outcomes were the absolute risk difference between matched pairs in receiving hospital care, supportive home care or hospital death.

Results In the No-RAl group, we identified 36238 pairs who received early and not-early palliative care. Those in the early palliative care group versus not-early group had a lower absolute risk difference of dying in hospital $(-10.0 \%)$ and receiving hospital care $(-10.4 \%)$ and a higher absolute risk difference of receiving supportive home care $(23.3 \%)$. In the Yes-RAl group, we identified 3586 pairs, where results were similar in magnitude and direction.

Conclusions Cancer decedents who received palliative care earlier than 6 months before death compared with those who did not had a lower absolute risk difference of receiving hospital care and dying in hospital, and an increased absolute risk difference of receiving supportive home care in the last month of life.

\section{INTRODUCTION}

Early palliative care is purported to improve quality of life and also avoid unnecessary acute care use, and thus reduce health system costs. Several randomised trials on patients with advanced cancer have shown that early palliative care reduced symptoms and some even had survival benefits. ${ }^{1-3}$ This evidence
Strengths and limitations of this study

- This large population-based cohort study of all cancer decedents in Ontario, Canada from 2004 to 2014 uses consistent exposure and outcome definitions over a long period of time, which provides high external validity in real-world settings.

- The study used propensity scores to match decedents who received palliative care earlier than 6 months before death compared with those who did not, thereby reducing selection bias among those who receive early palliative care.

- Our study included and controlled for previously unmeasured confounders known to be associated with receipt of early palliative care (ie, worse pain, Activities of Daily Living (ADL) dependency, depression, cognitive decline and health instability) derived from home care assessment data.

- The study matches those who have similar propensity to have received early palliative care, but this may not represent the entire population of cancer decedents.

- The study does not directly measure patient preferences, which is a confounder for use of early palliative care.

led to the oncology clinical practice guideline that supports the early integration of palliative care with standard oncological care. ${ }^{45}$ However, the evidence is mixed as to whether it reduces health services utilisation outcomes at end of life. There are trials that show that resource utilisation at end of life is not different from 'usual care'.

In particular, many of the trials implemented palliative care interventions close to diagnosis in controlled study settings, which is difficult to implement in the real-world. For example, the US' Medicare Hospice Benefit requires a physician to certify an expected death within 6 months. ${ }^{6}$ Additionally, many observational studies have found positive 
associations between early palliative care and reduced likelihood to receive aggressive care at end of life (eg, reduced hospitalisations and hospital deaths)..$^{7-12}$ However, observational studies are limited by selection bias, namely those who get early palliative care may be different from those who do not (eg, are sicker or more symptomatic in ways that are unmeasured). This is summarised in a large systematic review on early palliative care interventions, which found mixed evidence of benefits and noted key methodological issues of selection bias, as well as large variation in the definitions of when 'early' began, the interventions themselves and usual care. ${ }^{13}$ Thus, the evidence that early palliative care reduces late-life acute care use (particularly when it does not begin at diagnosis) is unclear. This gap has important health resource planning and economic implications.

By examining patients with cancer in the universal health system of Ontario, Canada, we are able to address prior limitations, namely standardising definitions for 'early' palliative care, usual care and the palliative care intervention. Usual care in Ontario means that patients with cancer have access to publicly subsidised palliative care in the form of: a palliative care outpatient clinic (eg, multidisciplinary pain and symptom management clinic); palliative home care services by a nurse of personal care worker; or a family doctor providing palliative care via clinic or rarely via home visit. Generally, these three services are independent of one another and uncoordinated. ${ }^{14}$ This contrasts the community-based, multidisciplinary team approach of palliative care delivery found in the USA via home hospice care $^{6}$ or in the UK via Macmillan cancer support programme. ${ }^{15}$ Although a small minority of patients might have access to a multidisciplinary, specialist palliative care team that makes home visits or a residential hospice, especially if they lived in a major city, this is haphazard and accessed typically in the last weeks of life. ${ }^{16}$ If the patients were hospitalised, they could also receive a consult from a palliative care doctor individually or a multidisciplinary team (eg, admitted to a palliative care unit) in the hospital. Unfortunately, data show palliative care services are often used very late in the disease trajectory or not at all. For example, in Ontario, Canada, palliative care services are used in 50\% of all deaths for a median of 30 days before death. ${ }^{17}$ In the USA, statistics are very similar, where palliative care via the Medicare Hospice Benefit is used in $45 \%$ of all deaths for a median of 17 days before death. ${ }^{18}$

Specifically this study investigated the impact of receiving palliative care early (at least 6 months before death) versus not-early on outcomes in the last 30 days of life. We used propensity score matching to reduce selection bias in observational cohorts around receipt of early palliative care.

\section{METHODS}

\section{Study design and data sources}

We performed a population-based, retrospective cohort study of all cancer decedents in Ontario, Canada from
2004 to 2014. We used propensity score matching to match decedents having received palliative care early (ie, between 12 and 6 months before death) to those who did not (ie, received palliative care late or not at all). We linked administrative databases housed at Institute for Clinical Evaluative Sciences (ICES) (formally known as the ICES) including the: Ontario Cancer Registry (cancer diagnosis), Vital Statistics Registry (death date), Discharge Abstract Database (hospitalisations), National Ambulatory Care Reporting System (emergency department use), physician billings, Statistics Canada (sociodemographic data like income and rurality) and the Home Care Database, which includes all Resident Assessment Instrument-Home Care (RAI-HC) assessments. Datasets were linked using unique encoded identifiers and analysed at ICES.

\section{Study population}

We included decedents who had a cancer diagnosis in the Ontario Cancer Registry and a death caused by cancer as per the provincial Vital Statistics registry. Those whose cancer diagnosis was 6 months or less from death were excluded as they were not eligible for the exposure.

\section{Exposure}

In the exposure period (ie, between 12 and 6 months before death), ${ }^{19}$ access to early palliative care was defined as having received: homecare with an palliative care intent; a physician consult for palliative care in an inpatient admission (including complex continuing care), outpatient clinic or a home visit setting; or a hospitalisation where palliative care was listed as the main reason for admission, as per prior research. ${ }^{17}$ Once a patient was identified as having received early palliative care, they remained in the exposed group for analysis.

\section{Outcomes}

Outcomes were death in an acute care bed, and the aggregate measures of aggressive care and supportive home care in the last 30 days of life respectively. Aggressive care was defined as one or a combination of $\geq 1$ emergency department visit, hospital admission or intensive care unit (ICU) admission. ${ }^{20}$ Supportive home care was defined as one or a combination of physician house call for palliative care, end-of-life homecare nursing or end-of-life personal support at home. ${ }^{21}$ Each outcome was handled as a binary variable (yes/no).

\section{Statistical analysis}

To reduce selection bias for decedents who were exposed to early palliative care, we used propensity score matching to create a similar comparison group of unexposed decedents (not-early). The propensity score is an individual's probability of receiving early palliative care, given the values of their baseline measured covariates. Matching on the propensity score can estimate the effect of the intervention, which is unbiased by differences in the distributions of measured baseline covariates. ${ }^{22}{ }^{23}$ Our methods matches two individuals who have the same propensity 


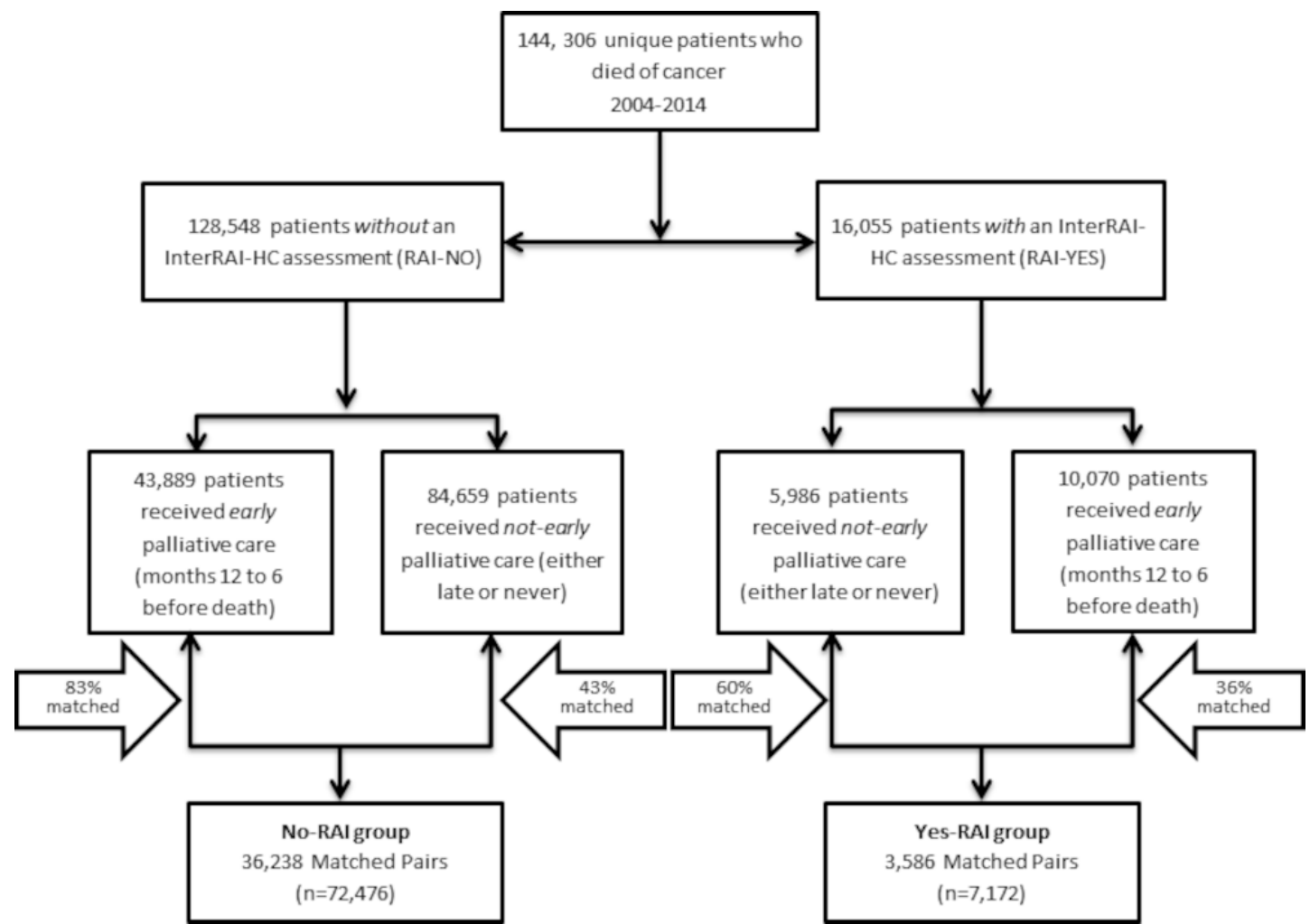

Figure 1 CONSORT diagram. CONSORT, Consolidated Standards of Reporting Trials; RAI-HC, Resident Assessment Instrument-Home Care.

to receive early palliative care in the exposure period, though one got early palliative care and one did not.

A priori we decided to examine the group who received long-stay home care services (ie, expected to receive at least 60 days of home care) and thus had an RAI-HC assessment in the exposure period separately. Of note, long-stay home care patients either received standard homecare (unexposed) or palliative homecare (exposed) services. This allowed us to control for additional confounders associated with receipt of early palliative care that are uniquely available in the RAI-HC. Therefore, we created two mutually exclusive groups of matched pairs and each pair consists of an exposed and unexposed decedent. One group is called the No-RAI group; the other the YesRAI group.

For the No-RAI group, all pairs were hard matched before the exposure period on: age at death, sex, cancer type, cancer stage (where available) and the logit of the propensity score (callipers of width less than or equal to 0.2 of the SD of the logit of the propensity score) ${ }^{2425} \mathrm{We}$ estimated the propensity score using a logistic regression model with exposure to early palliative care as the independent variable. The predictor variables in the propensity score regression included: income quintile, rurality, health region, prior hospital utilisation in months 24-12 before death, Deyo-modified Charlson Comorbidity Score in months 24-12 before death, index year of death, and having had radiation or cancer surgery. ${ }^{26}$

For the Yes-RAI group, we use additional data from the RAI-HC, which is a standardised assessment for all long stay home care patients in Ontario, corresponding to the Minimum Data Set in the USA. ${ }^{27}$ In addition to matching procedure noted above for the No-RAI group, pairs were hard matched on health instability using the Changes in Health, End-stage Disease, Signs and Symptoms (CHESS) scale. ${ }^{28} 29$ The following items were also included in the propensity score regression: functional performance and dependency using the Activities of Daily Living (ADL) Self-performance Hierarchy Scale ${ }^{30}$; depression using the Depression Rating Scale ${ }^{31}$; cognitive impairment using the Cognitive Performance Scale ${ }^{32}$; pain intensity using the Pain Scale ${ }^{33}$ and living with a primary or secondary caregiver (yes/no).

Because the distributions of covariates were well balanced and not statistically different after matching the exposed and unexposed patients in both the No-RAI and Yes-RAI groups, we did not need to employ any regression methods for examining the exposureoutcomes relationship; thus for each outcome, we determined the absolute risk difference between the matched exposed and unexposed individuals in both Yes-RAI and No-RAI groups. ${ }^{34}$ We used McNemar's test to determine statistical significance of the estimated risk difference. ${ }^{35}$ Differences in risk between the exposure and control groups for each outcome were assessed using standardised differences. Standardised differences are more appropriate to use in this population-based study as they are not influenced by sample size (unlike $p$ values). Analysis was performed using SAS Enterprise Guide, V.7.1 (SAS Institute). 
As a sensitivity analysis, we divided the not-early groupthat is, unexposed group-into late palliative care (ie, only received palliative care in the last 6 months of life) and never received palliative care. We conducted a sensitivity analysis to examine early versus late and early versus never subgroups separately in an attempt to control for unmeasured patient preferences. The hypotheses were that some patients may refuse palliative care altogether (which would appear in our data as never receiving any palliative care services even near death); and other patients might have been willing to receive palliative care but were offered it late (which would appear in our data as receiving it in the final 6 months of life). Analysing the late users to the early users specifically was an attempt to separate out those patients who might have refused palliative care as per their preference. The study is reported using the Strengthening the Reporting of Observational Studies in Epidemiology framework for observational studies. ${ }^{36}$

\section{Patient and public involvement}

Patients and the public were not involved this research.

\section{RESULTS}

\section{Patients}

After excluding those with a cancer diagnosis within 6 months of death $(n=84673)$, our overall eligible cohort consisted of 144306 cancer decedents in Ontario between 2004 and 2014, of which $53959(37.4 \%)$ received early palliative care $12-6$ months before death. Eighty-nine per cent $(n=128248)$ of the overall cohort did not have an RAI-HC in the exposure period (No-RAI) and they were matched separately than the $11 \%(\mathrm{n}=16058)$ who did have the assessment (Yes-RAI) (figure 1). Baseline characteristics before propensity score matching are shown in online supplemental appendix S1, and those after propensity score matching are shown in table 1 .

In the No-RAI group, we matched $82.6 \%$ of patients who received early palliative care for a total of 36238 matched pairs. After matching, the decedent covariate distributions were nearly identical between the two groups. For instance, average age was $69,23.5 \%$ had lung cancer and $14.2 \%$ had stage IV disease. In the No-RAI group, during the exposure period the group received 53787 palliative care services, of which approximately $40 \%$ of services were homecare and $40 \%$ were outpatient physician billings. The first initiation of early palliative care was about 300 days before death. In the last 6 months of life, the early group received 91321 palliative care services $(30 \%$ home care, $33 \%$ physician consults and $24 \%$ hospital), whereas the late group received 63994 palliative care services (25\% home care, $35 \%$ physician consults and $29 \%$ hospital admissions).

In the Yes-RAI group, we matched $59.9 \%$ of patients who received regular homecare in the exposure period to those who received palliative homecare services in the exposure period for a total of 3586 matched pairs.
After matching, the decedent covariate distributions were nearly identical between the two groups. For instance, $11.8 \%$ had moderate to severe health instability using the CHESS score, $6.8 \%$ were fully dependent on their ADLs and $11.0 \%$ had moderate-to-severe pain. In the Yes-RAI group, during the exposure period the group received 5468 palliative care services, of which nearly half were homecare services. The first initiation of early palliative care was about 330 days before death. In the last 6 months of life, the early group received 8484 palliative care services (same distributions as No-RAI group) whereas the late group received 4664 palliative care services $(16 \%$ home care, $38 \%$ physician consults and 37\% hospital admissions).

\section{Aggressive care}

Among matched pairs in the No-RAI group, those who received early palliative care had lower risk difference of the aggressive care outcomes compared with the not-early group (table 2). $38.1 \%$ of the early palliative care decedents died in hospital, compared with $48.1 \%$ of the nonearly palliative care group, resulting in a lower absolute risk difference of $10.0 \%$. Similarly, the aggregate measure of aggressive care was lower by $10.4 \%$ among early palliative care decedents. The early palliative care decedents have a lower absolute risk difference of an emergency department visit $(9.7 \%)$, hospital admission $(10.1 \%)$ and ICU admission (4.4\%) in the last month of life compared with the not-early group.

Among matched pairs in the Yes-RAI groups, we found similar results in the direction and magnitude of the absolute risk differences favouring early palliative care. Note, McNemar's tests for matched pairs were significant ( $p<0.0001$ for all measures). Further, the sensitivity analyses in the Yes-RAI and No-RAI groups separately, looking at matched pairs of early vs late palliative care and early versus never palliative care, respectively, showed that the early palliative care group consistently had lower absolute risk differences for all outcomes, in similar magnitudes (online supplemental appendix S2).

\section{Supportive home care}

Among the matched pairs in the No-RAI group, those who received early palliative care had higher risk of receiving supportive home care outcomes compared with the not-early group. (table 3 ) The aggregate measure of supportive home care was higher by $23 \%$ among early palliative care decedents vs not-early decedents. $56.2 \%$ of the early palliative care decedents had any end-of-life home care nursing in the last 30 days, compared with $34.0 \%$ of the non-early palliative care group, resulting in a lower absolute risk difference of $22.2 \%$. The early palliative care decedents have a higher absolute risk of having a physician house call $(10.2 \%)$ and an end-of-life personal support worker in the last month of life $(16.0 \%)$ versus not-early decedents.

Among the matched pairs in the Yes-RAI groups, we found similar trends in direction, but at larger 
Table 1 Demographics of early versus not-early palliative care

\section{After propensity score matching}

\begin{tabular}{|c|c|c|c|}
\hline \multicolumn{2}{|l|}{ No-RAI } & \multicolumn{2}{|l|}{ Yes-RAI } \\
\hline $\begin{array}{l}\text { Not early } \\
\text { palliative care } \\
(\mathrm{N}=36238)\end{array}$ & $\begin{array}{l}\text { Early palliative } \\
\text { care }(\mathrm{N}=36238)\end{array}$ & $\begin{array}{l}\text { Not early } \\
\text { palliative care } \\
(\mathrm{N}=3586)\end{array}$ & $\begin{array}{l}\text { Early palliative } \\
\text { care }(\mathrm{N}=3568)\end{array}$ \\
\hline N (\%) & N (\%) & N (\%) & N (\%) \\
\hline
\end{tabular}

Variables that were hard matched

Mean age $\pm S D$

$\begin{array}{llllll}69.43 \pm 12.84 & 69.36 \pm 12.87 & 0.01 & 76.63 \pm 11.25 & 76.46 \pm 11.19 & 0.01\end{array}$

Female

17702 (48.8)

$17702(48.8) \quad 0.00$

$1826(50.9)$

1826 (50.9)

0.00

Cancer type at diagnosis

\begin{tabular}{|c|c|c|c|c|c|c|}
\hline Breast & $4126(11.4)$ & $4126(11.4)$ & 0.00 & $433(12.1)$ & $433(12.1)$ & 0.00 \\
\hline Colorectal & $5266(14.5)$ & $5266(14.5)$ & 0.00 & $722(20.1)$ & $722(20.1)$ & 0.00 \\
\hline Haematology & $2982(8.2)$ & $2982(8.2)$ & 0.00 & $479(13.4)$ & $479(13.4)$ & 0.00 \\
\hline Prostate & $3053(8.4)$ & $3053(8.4)$ & 0.00 & $486(13.6)$ & $486(13.6)$ & 0.00 \\
\hline \multicolumn{7}{|l|}{ Stage at diagnosis } \\
\hline Unavailable & $24631(68.0)$ & $24631(68.0)$ & 0.00 & $2749(76.7)$ & $2749(76.7)$ & 0.00 \\
\hline \multicolumn{7}{|l|}{ CHESS Score (when RAI-HC completed) } \\
\hline No health instability & - & - & - & $921(25.7)$ & $921(25.7)$ & 0.00 \\
\hline Low health instability & - & - & - & $2242(62.5)$ & $2242(62.5)$ & 0.00 \\
\hline Lowest income quintile & $7058(19.5)$ & $7146(19.7)$ & 0.01 & $776(21.6)$ & $790(22.0)$ & 0.01 \\
\hline Highest income quintile & $7102(19.6)$ & $7130(19.7)$ & 0.00 & $626(17.5)$ & $622(17.3)$ & 0.00 \\
\hline Lives in Rural Community & $5206(14.4)$ & $5236(14.4)$ & 0.00 & $579(16.1)$ & $568(15.8)$ & 0.01 \\
\hline Deyo-Charlson Comorbidity Score $(\geq 1)$ & $12026(33.2)$ & $12540(34.6)$ & 0.03 & $1483(41.4)$ & $1426(39.8)$ & 0.08 \\
\hline Had Radiation since diagnosis & $22337(61.6)$ & $21982(60.7)$ & 0.02 & $1894(52.8)$ & $1950(54.4)$ & 0.03 \\
\hline Had cancer surgery since diagnosis & $16339(45.1)$ & $15701(43.3)$ & 0.04 & $1780(49.6)$ & $1716(47.9)$ & 0.04 \\
\hline $\begin{array}{l}\text { Mean hospital days (between } 2 \text { and } 1 \\
\text { years before death) } \pm S D\end{array}$ & $0.82 \pm 1.12$ & $0.84 \pm 1.17$ & 0.01 & $0.94 \pm 1.21$ & $0.91 \pm 1.16$ & 0.03 \\
\hline \multicolumn{7}{|l|}{ Disease duration } \\
\hline Minor-major depression & - & - & - & $496(13.8)$ & $429(10.0)$ & 0.06 \\
\hline Moderate-to-severe cognitive impairment & - & - & - & $373(10.4)$ & $363(10.1)$ & 0.01 \\
\hline Moderate-to-severe pain & - & - & - & $391(10.9)$ & $398(11.1)$ & 0.01 \\
\hline Caregiver present at Home & - & - & - & $2279(63.6)$ & $2264(63.1)$ & 0.01 \\
\hline
\end{tabular}

CHESS, Changes in Health, End-stage Disease, Signs and Symptoms; RAI-HC, Resident Assessment Instrument-Home Care. 
Table 2 Aggressive care measures in decedents with or without an RAl assessment

\begin{tabular}{|c|c|c|c|c|c|c|c|c|}
\hline & \multicolumn{4}{|l|}{ NO-RAI } & \multicolumn{4}{|l|}{ YES-RAI } \\
\hline & \multirow{2}{*}{$\begin{array}{l}\begin{array}{l}\text { Early } \\
\text { palliative care }\end{array} \\
\mathrm{N}=36238(\%)\end{array}$} & \multirow{2}{*}{$\begin{array}{l}\text { Not early } \\
\text { palliative care } \\
\mathrm{N}=36238(\%)\end{array}$} & \multirow{2}{*}{$\begin{array}{l}\text { Absolute } \\
\text { risk } \\
\text { difference } \\
(\%) \text { (early } \\
\text { vs not } \\
\text { early)* }^{\star}\end{array}$} & \multirow[b]{2}{*}{ SD } & \multirow{2}{*}{ 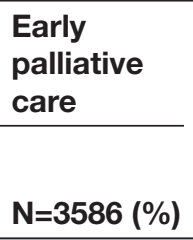 } & \multirow{2}{*}{$\begin{array}{l}\begin{array}{l}\text { Not early } \\
\text { palliative } \\
\text { care }\end{array} \\
\mathrm{N}=3586(\%)\end{array}$} & \multirow{2}{*}{$\begin{array}{l}\text { Absolute } \\
\text { risk } \\
\text { difference } \\
\text { (\%) (early } \\
\text { vs not } \\
\text { early)* }\end{array}$} & \multirow[b]{2}{*}{ SD } \\
\hline & & & & & & & & \\
\hline $\begin{array}{l}\text { Aggressive care (any } \\
\text { one or combination of } \\
\text { the following three) }\end{array}$ & $18822(51.9)$ & 22586 (62.3) & -10.4 & 0.21 & 1718 (47.9) & 2089 (58.3) & -10.4 & 0.21 \\
\hline $\begin{array}{l}\text { At least } 1 \text { ED visits } \\
\text { within last } 30 \text { days }\end{array}$ & $15550(42.9)$ & 19075 (52.6) & -9.7 & 0.21 & $1454(40.5)$ & $1827(50.9)$ & -10.4 & 0.21 \\
\hline
\end{tabular}

*McNemar's test was significant to $<0.0001$ for all measures.

ED, emergency department; RAI, Resident Assessment Instrument.

magnitudes: a $37.8 \%$ higher absolute risk difference of having any one of the three supportive home care outcomes. Note, McNemar's tests for matched pairs were significant $(\mathrm{p}<0.0001$ for all measures $)$. Further the sensitivity analyses, examining early versus late and early versus never palliative care matched pairs separately, showed that early palliative care consistently had higher absolute risk differences for all outcomes (online supplemental appendix S3).

\section{DISCUSSION}

In our population-based cohort of 114306 cancer decedents, a propensity score matched cohort of those who received palliative care earlier than 6 months before death compared with those who did not had a: lower absolute risk of dying in hospital by $10 \%-13 \%$, lower absolute risk of an aggressive care outcome in the last month of life by $10 \%$, and higher absolute risk of having a supportive care outcome in the last month of life by 23\%-38\%. While prior randomised trials provided high internal validity within controlled settings, our approach provides high external validity in real-world settings. Bolstering the credibility that early palliative care is beneficial is the consistency of our findings across 2004-2014, which predate the publication of seminal randomised trials $^{1-3}$; and the use of a population-based cancer cohort,

Table 3 Supportive home care measures in decedents with or without an RAl assessment

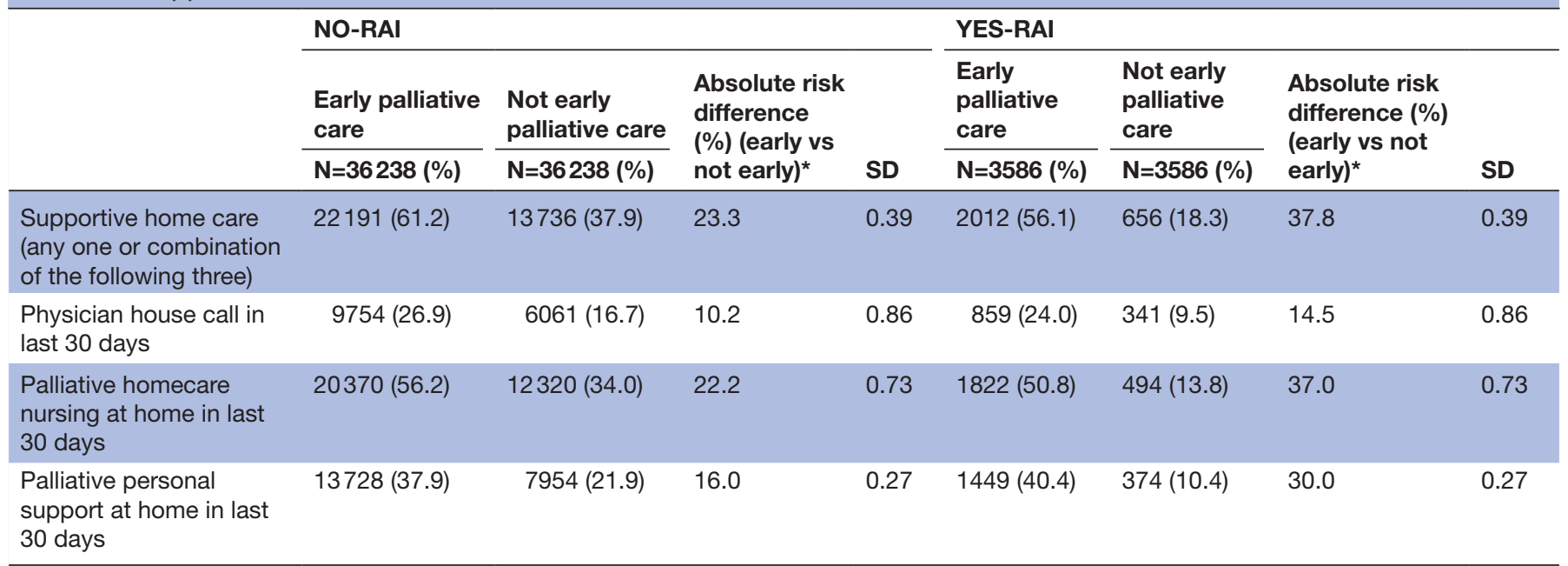

*McNemar's test was significant to $<0.0001$ for all measures.

RAI, Resident Assessment Instrument. 
meaning the findings were not a result of a particular cancer centre, intervention programme or cancer type.

This study addressed some of the noted gaps in prior research: it uses consistent exposure and outcome definitions over a long period of time and uses a large population-based cohort of all cancer types. Moreover, by using data from the RAI-HC, our study was able to control for previously unmeasured confounders known to be associated with receipt of early palliative care, such as worse pain, ADL dependency, depression, cognitive decline and health instability. This seeks to address selection bias in prior observational studies where those receiving palliative care might be different (eg, worse symptoms or have worse health instability) than those who do not. Our results were consistent with and without matching for RAI-HC variables. Moreover in our sensitivity analysis, where we examined early versus late subgroup separately (where the assumption was that both groups of patients were amendable to receiving palliative care), the findings were consistent with our overall study results, further supporting the benefits of early palliative care.

The results of this study support policies to enable earlier access to end-of-life homecare services and outpatient physician services for palliative care. In particular, policies that prohibit the access of palliative care services unless one forgoes curative treatments or is certified as expected to die within 6 months or less are disincentives to earlier and concurrent access to palliative care. For instance in the USA, the Medicare Hospice Benefit provides access to community-based hospice care but requires a physician to certify a life expectancy of less than 6 months and a patient commitment to forgo curative treatment. ${ }^{37}$ Besides policies, education is critical because research shows that patient preferences sometimes change over time, ${ }^{38}$ and that clinicians play an important role in introducing and initiating palliative care (eg, Serious Illness Conversations) and helping patients make informed treatment decisions about goals of care for end of life. ${ }^{39}$

Our study has limitations. The propensity score matched design means we are comparing among those who are likely to have received early palliative care, but this may not represent the entire population of cancer decedents. We did not directly measure patient, family or provider preferences, which would be useful to control for in future studies. We used administrative data and billing codes to determine access to palliative care, which does not always represent the true intent of care provided, and we did not include billings from long-term care settings. As well, future research should examine outcomes of health system costs, health resource utilisation or patient and caregiver well-being.

In conclusion, across an 11-year population-based, cancer cohort, those who received early palliative care (before 6 months of death) compared with a matched cohort of those who did not, were more likely to receive supportive home care and less likely to receive hospital care in the last month of life. Our findings suggest that policies and education strategies to support the delivery of early palliative care might reduce the risk of dying in hospital and receiving aggressive care at end of life in real-world settings.

Author affiliations

${ }^{1}$ Department of Oncology, McMaster University, Hamilton, Ontario, Canada

${ }^{2}$ Institute for Clinical Evaluative Sciences, Toronto, Ontario, Canada

${ }^{3}$ Dalla Lana School of Public Health, University of Toronto, Toronto, Ontario, Canada

${ }^{4}$ Department of Family Medicine, Dalhousie University, Halifax, Nova Scotia, Canada

${ }^{5}$ School of Population and Public Health, University of British Columbia, Vancouver,

British Columbia, Canada

${ }^{6}$ Department of Health Sciences, Wilfrid Laurier University, Waterloo, Ontario,

Canada

${ }^{7}$ Sunnybrook Health Sciences Centre, Toronto, Ontario, Canada

${ }^{8}$ British Columbia Cancer Agency, Vancouver, British Columbia, Canada

${ }^{9}$ Department of Oncology, University of Calgary, Calgary, Alberta, Canada

Twitter Hsien Seow @HSeowPhD and Kimberlyn McGrail @kimchspr

Acknowledgements The authors would like to acknowledge the following people for their feedback during the preparation of this manuscript: Erin 0'Leary and Reka Petaky.

Contributors HS, LB and RS conceived the hypothesis, acquired the data, and designed the analysis plan. UEO performed the analyses. HS wrote the manuscript. All authors interpreted the data, critically revised the manuscript for important intellectual content and approved the final manuscript. HS, UEO and RS had full access to all of the data in the study and can take responsibility for the integrity of the data and the accuracy of the data analysis. The corresponding author attests that all listed authors meet authorship criteria and that no others meeting the criteria have been omitted.

Funding This work is funded by the Canadian Centre for Applied Research in Cancer Control (ARCC). ARCC receives core funding from the Canadian Cancer Society Research Institute (grant \#2015-703549). The lead author is also supported by the Canada Research Chairs program. The study used databases maintained by the Institute for Clinical Evaluative Sciences, which receives funding from the Ontario Ministry of Health and Long Term Care. The opinions, results and conclusions reported in this paper are those of the authors and are independent from the funding and data providing sources.

Competing interests None declared.

Patient consent for publication Not required.

Ethics approval The study was approved by the Hamilton Integrated Research Ethics Board (\#3039).

Provenance and peer review Not commissioned; externally peer reviewed.

Data availability statement Data may be obtained from a third party and are not publicly available. Data may be obtained from a third party and are not publicly available. A data request can be sent to ICES (formerly the Institute for Clinical Evaluative Sciences): https://www.ices.on.ca/About-ICES/ICES-Contacts-andLocations/contact-form.

Supplemental material This content has been supplied by the author(s). It has not been vetted by BMJ Publishing Group Limited (BMJ) and may not have been peer-reviewed. Any opinions or recommendations discussed are solely those of the author(s) and are not endorsed by BMJ. BMJ disclaims all liability and responsibility arising from any reliance placed on the content. Where the content includes any translated material, BMJ does not warrant the accuracy and reliability of the translations (including but not limited to local regulations, clinical guidelines, terminology, drug names and drug dosages), and is not responsible for any error and/or omissions arising from translation and adaptation or otherwise.

Open access This is an open access article distributed in accordance with the Creative Commons Attribution Non Commercial (CC BY-NC 4.0) license, which permits others to distribute, remix, adapt, build upon this work non-commercially, and license their derivative works on different terms, provided the original work is properly cited, appropriate credit is given, any changes made indicated, and the use is non-commercial. See: http://creativecommons.org/licenses/by-nc/4.0/.

ORCID iD

Hsien Seow http://orcid.org/0000-0001-6701-1714 


\section{REFERENCES}

1 Zimmermann C, Swami N, Krzyzanowska M, et al. Early palliative care for patients with advanced cancer: a cluster-randomised controlled trial. Lancet 2014;383:1721-30.

2 Temel JS, Greer JA, Muzikansky A, et al. Early palliative care for patients with metastatic non-small-cell lung cancer. $N$ Engl $\mathrm{J}$ Med 2010;363:733-42.

3 Bakitas M, Lyons KD, Hegel MT, et al. Effects of a palliative care intervention on clinical outcomes in patients with advanced cancer: the project ENABLE II randomized controlled trial. JAMA 2009;302:741-9.

4 Ferrell BR, Temel JS, Temin S, et al. Integration of palliative care into standard oncology care: ASCO clinical practice guideline update summary. J Oncol Pract 2017;13:119-21.

5 Smith TJ, Temin S, Alesi ER, et al. American Society of clinical oncology provisional clinical opinion: the integration of palliative care into standard oncology care. J Clin Oncol 2012;30:880-7.

6 Centers for Medicare \& Medicaid Services. Medicare hospice benefits. Baltimore; 2013

7 Qureshi D, Tanuseputro P, Perez R, et al. Early initiation of palliative care is associated with reduced late-life acute-hospital use: a population-based retrospective cohort study. Palliat Med 2019;33:269216318815794.

8 McNamara BA, Rosenwax LK, Murray K, et al. Early admission to community-based palliative care reduces use of emergency departments in the ninety days before death. $J$ Palliat Med 2013;16:774-9.

9 Pellizzari M, Hui D, Pinato E, et al. Impact of intensity and timing of integrated home palliative cancer care on end-of-life hospitalization in northern Italy. Support Care Cancer 2017;25:1201-7.

10 Wright CM, Youens D, Moorin RE. Earlier initiation of communitybased palliative care is associated with fewer unplanned hospitalizations and emergency department presentations in the fina months of life: a population-based study among cancer decedents. $J$ Pain Symptom Manage 2018;55:745-54.

11 Seow H, Barbera L, Howell D, et al. Using more end-of-life homecare services is associated with using fewer acute care services: a population-based cohort study. Med Care 2010;48:118-24.

12 Spilsbury K, Rosenwax L, Arendts G, et al. The impact of community-based palliative care on acute hospital use in the last year of life is modified by time to death, age and underlying cause of death. A population-based retrospective cohort study. PLoS One 2017;12:e0185275.

13 Davis MP, Temel JS, Balboni T, et al. A review of the trials which examine early integration of outpatient and home palliative care for patients with serious illnesses. Ann Palliat Med 2015;4:99-121.

14 Brazil K, Bainbridge D, Sussman J, et al. Coordination of palliative cancer care in the community: "unfinished business". Support Care Cancer 2009;17:819-28.

15 Corner J, Halliday D, Haviland J, et al. Exploring nursing outcomes for patients with advanced cancer following intervention by Macmillan specialist palliative care nurses. J Adv Nurs 2003;41:561-74.

16 Seow H, Brazil K, Sussman J, et al. Impact of community based, specialist palliative care teams on hospitalisations and emergency department visits late in life and hospital deaths: a pooled analysis. BMJ 2014;348:g3496.

17 Tanuseputro P, Budhwani S, Bai YQ, et al. Palliative care delivery across health sectors: a population-level observational study. Palliat Med 2017;31:247-257.

18 National Hospice and Palliative Care Organization. NHPCO facts and figures: hospice care in America. Alexandria, Virginia; 2016.
19 Romo RD, Lynn J. The utility and value of the "surprise question" for patients with serious illness. CMAJ 2017;189:E1072-3.

20 Earle CC, Park ER, Lai B, et al. Identifying potential indicators of the quality of end-of-life cancer care from administrative data. J Clin Oncol 2003;21:1133-8.

21 Warren JL, Barbera L, Bremner KE, et al. End-Of-Life care for lung cancer patients in the United States and Ontario. J Natl Cancer Inst 2011;103:853-62.

22 Rosenbaum PR, RUBIN DB. The central role of the propensity score in observational studies for causal effects. Biometrika 1983;70:41-55.

23 Rosenbaum P, Rubin D. Constructing a control group using multivariate matched sampling methods that incorporate the propensity score. The American Statistician 1985;39:33-8.

24 Austin PC. Balance diagnostics for comparing the distribution of baseline covariates between treatment groups in propensity-score matched samples. Stat Med 2009;28:3083-107.

25 Austin PC. Type I error rates, coverage of confidence intervals, and variance estimation in propensity-score matched analyses. Int $\mathrm{J}$ Biostat 2009;5:Article 13.

26 Henson LA, Gomes B, Koffman J, et al. Factors associated with aggressive end of life cancer care. Support Care Cancer 2016;24:1079-89.

27 Hirdes JP, Ljunggren G, Morris JN, et al. Reliability of the interRAI suite of assessment instruments: a 12-country study of an integrated health information system. BMC Health Serv Res 2008;8:1-11.

28 Hirdes JP, Poss JW, Mitchell L, et al. Use of the interRAI CHESS scale to predict mortality among persons with neurological conditions in three care settings. PLoS One 2014;9:e99066.

29 Hirdes JP, Frijters DH, Teare GF. The MDS-CHESS scale: a new measure to predict mortality in institutionalized older people. J Am Geriatr Soc 2003;51:96-100.

30 Morris JN, Fries BE, Morris SA. Scaling ADLs within the MDS. J Gerontol A Biol Sci Med Sci 1999;54:M546-53.

31 Burrows AB, Morris JN, Simon SE, et al. Development of a minimum data set-based depression rating scale for use in nursing homes. Age Ageing 2000;29:165-72.

32 Morris JN, Fries BE, Mehr DR, et al. MDS cognitive performance scale. J Gerontol 1994:49:M174-82.

33 Fries BE, Simon SE, Morris JN, et al. Pain in U.S. nursing homes: validating a pain scale for the minimum data set. Gerontologist 2001:41:173-9.

34 Austin PC. Primer on statistical interpretation or methods report card on propensity-score matching in the cardiology literature from 2004 to 2006: a systematic review. Circ Cardiovasc Qual Outcomes 2008;1:62-7.

35 Austin PC. A critical appraisal of propensity-score matching in the medical literature between 1996 and 2003. Stat Med 2008;27:2037-49.

36 von Elm E, Altman DG, Egger M, et al. The strengthening the reporting of observational studies in epidemiology (STROBE) statement: guidelines for reporting observational studies. Int J Surg 2014:12:1495-9.

37 Carlson MDA, Morrison RS, Bradley EH. Improving access to hospice care: Informing the debate. J Palliat Med 2008;11:438-43.

38 Gomes B, Calanzani N, Gysels M, et al. Heterogeneity and changes in preferences for dying at home: a systematic review. BMC Palliat Care 2013;12:7.

39 Paladino J, Bernacki R, Neville BA, et al. Evaluating an intervention to improve communication between oncology clinicians and patients with life-limiting cancer: a cluster randomized clinical trial of the serious illness care program. JAMA Oncol 2019;5:801-9. 